\title{
Impact of Extreme Weather Events on Sub-Saharan African Child and Adolescent Mental Health: A Protocol for a Systematic Review
}

\author{
Hanna-Andrea Rother ${ }^{1, *(\mathbb{D}, \text { Ruth A. Etzel }}{ }^{2}{ }^{\mathbb{D}}$, Mary Shelton ${ }^{3}$, Jerome A. Paulson ${ }^{4,5}$, \\ R. Anna Hayward ${ }^{6}$ and Linda C. Theron ${ }^{7}$ (D) \\ 1 Division of Environmental Health, School of Public Health and Family Medicine, University of Cape Town, \\ Observatory 7925, South Africa \\ 2 Milken Institute, School of Public Health, The George Washington University, Washington, DC 20052, USA; \\ retzel@earthlink.net \\ 3 Health Sciences Library, University of Cape Town, Observatory 7925, South Africa; mary.shelton@uct.ac.za \\ 4 Department of Environmental \& Occupational Health, School of Public Health and Health Services, \\ The George Washington University, Washington, DC 20052, USA; jerry@envirohealthdoctor.com \\ 5 Department of Pediatrics, School of Medicine and Health Sciences, The George Washington University, \\ Washington, DC 20052, USA \\ 6 School of Social Welfare, Health Sciences Center, Stony Brook University, Stony Brook, NY 11794-8231, USA; \\ anna.hayward@stonybrook.edu \\ 7 Department of Educational Psychology/Centre for the Study of Resilience, Faculty of Education, \\ University of Pretoria, Pretoria 0027, South Africa; linda.theron@up.ac.za \\ * Correspondence: andrea.rother@uct.ac.za; Tel.: +27-21-406-6721
}

Received: 9 April 2020; Accepted: 4 May 2020; Published: 12 May 2020

\begin{abstract}
Sub-Saharan Africa (SSA) has been identified by the Intergovernmental Panel on Climate Change (IPCC) as being the most vulnerable region to climate change impacts. A major concern is the increase in extreme weather events (EWE) such as storms, floods, droughts, heatwaves, wildfires, and landslides in SSA and their potential to affect the health and well-being of children and adolescents. The objective of this systematic review is to examine the direct and indirect impacts of EWE on the mental health of children and adolescents living in SSA, in order to inform protective adaptation strategies and promote resilience. A meta-analysis will not be possible, since the assumption is that limited studies have been published on the EWE-associated mental health impacts on children and adolescents living in SSA and that those studies that are available are heterogenous. There is acknowledgement in the global literature of the need to highlight child and adolescent mental health more prominently in climate change health strategies and policies. It is vital that adaptation strategies are informed by research on risk prevention and promotion of resilience to ensure the mental health of children and adolescents is protected.
\end{abstract}

Keywords: extreme weather events; climate change; children; adolescents; pediatrics; mental health; resilience; sub-Saharan Africa; global warming; adaptation

\section{Introduction}

Sub-Saharan Africa (SSA), which is developing significantly and boasts extensive diversity culturally, ecologically and climatically, has been identified by the Intergovernmental Panel on Climate Change (IPCC) as being the most vulnerable region to climate change impacts, both directly and indirectly [1]. One major impact of climate change is an increase in extreme weather events (EWE). These events are expected to adversely impact mental health, especially that of children and 
adolescents [2-4]. What is less understood is the impact of EWE on sub-Saharan African children's and adolescents' mental health. The focus of the proposed review, therefore, is on the direct and indirect impacts of EWE on child and adolescent mental health in SSA, highlighting evidence gaps for future research, as well as the factors and processes that protect children and adolescents in SSA from negative mental health outcomes relating to EWE exposure. A resilience perspective is crucial to all efforts to optimally prepare and respond to how EWE impact child and adolescent mental health [5].

The emphasis on mental health, rather than illness, transcends the health risks associated with EWE to include investigation of what is known about factors that protect mental health in the face of EWE and promote child and adolescent resilience. Children are the canaries in the climate change mine shaft. We currently have limited empirical evidence of the health impacts on children and particularly in relation to mental health [6]. The 2019 report on the Lancet Countdown on Health and Climate Change drew attention to the need to prevent children's health from being defined by climate change impacts. A focus on mental health impacts from EWE was absent, however. Even though scholars and practitioners have begun to acknowledge the role of resilience in the mental health of children exposed to EWE [7], most studies are preoccupied with risk factors rather than resilience-enabling ones [4]. Will we have to wait another 10-20 years for research to show these impacts before prevention measures are adequately in place, or are there data available to invoke the precautionary principle to protect children's mental health from EWE? Adaptation plans and resilience processes need information about children's vulnerabilities and resources to adequately put protection measures in place. With the assumption that "adaptation is fundamentally about risk management" the key issue is that we need clarity on what the risks are, along with what buffers these risks, in order to put relevant protection mechanisms into place [1].

The global rise in EWE (e.g., storms, floods, droughts, heatwaves, wildfires, landslides) [8] has the potential to influence (directly and indirectly) the health and well-being of affected communities in different ways, which in turn influences the health of children and adolescents $[4,9,10]$. The direct and negative impacts include decreased mental well-being, impacts on those with existing mental disorders, physical injuries, and impacts on respiratory, cardiovascular and reproductive systems. The indirect impacts include displacement, migration, famine and malnutrition, degradation or destruction of health and social care systems, conflict, and economic and social losses [11-16] all of which can affect the mental health and well-being of children and adolescents.

\subsection{Extreme Weather Events in Sub-Saharan Africa}

Extreme weather events linked to climate change are increasing in frequency and severity globally, including in SSA [17-19]. These events, which vary geographically, are predicted to affect food and water security and the nutritional status of children, as well as to increase aeroallergens, increase the incidence of vector-borne diseases, and increase injuries [20,21]. There is regional variation in the patterns of climate change within the four main regions - Central Africa, East Africa, West Africa and Southern Africa-which will impact on differing EWEs to occur in the different regions. Given the climate projections for SSA, weather changes will include, temperature changes-that is, warming (especially for inland subtropics); extreme heat events-that is, temperature rises (particularly in tropical West Africa); and precipitation changes-that is, an increase in drier and a decrease in wetter conditions in different SSA regions (i.e., increase in aridity), and changes in rainfall patterns (e.g., increasing in East Africa (wetter) - and decreasing in southern Africa (dryer) [22,23]. The impact of these weather changes will lead to continued and increasing EWE such as, increasing heat-wave days and high fire-danger days, heavy precipitation (e.g., increasing flooding in East Africa), an increase in cyclones in South East African Coastal areas, increase in heavy rain storms and increasing droughts in Southern Africa [22-26]. The physical risks that EWE will impose on children and adolescents include dehydration, drowning, physical injury, exposure to polluted water and increased violence [17]. 


\subsection{Defining Children and Adolescents}

In this review, we define children and adolescents within practiced conventions. Children are considered to be under 10 years and adolescents from 10-19 years. This is in recognition that the literature forming part of this review will have used this convention. We, however, wish to acknowledge that recently, Sawyer and colleagues (2018) have argued that the age range of adolescence be extended from 10-19 to 10-24 to better fit with how adolescence plays out in the 21st century [27]. This extended range fits better with traditional African definitions of youth (i.e., young people up to the age of 35) and should be promoted in future research and reviews on SSA [28]. Furthermore, conceptualizing adolescence more generously as 10-24 fits with the liminal reality of most SSA young people, namely that socioeconomic stressors delay socially sanctioned enactments of adulthood, such as purchasing property or living independently [29]. We hope that in the future more literature will cite studies that include adolescents until the age of 24 .

Children and adolescents are particularly at high risk from the potential health effects associated with climate change in general and from EWE in particular; including mortality [14,30]. Despite this, children and adolescents (including those in SSA) are a marginal focus of international negotiations, other relevant discussions and often excluded from adaptation strategies [31].

\subsection{Short and Long-Term Health Risks for Children and Adolescents Exposed to EWE}

In the climate change literature, there is an indication that all EWE pose potential negative mental health impacts on those exposed (both those with and without pre-existing mental health disorders). Children and adolescents are disproportionately vulnerable to the health impacts from climate change and resulting EWE [7,32-35]. More to the point, SSA children and adolescents constitute most of the people of SSA [36] and are the future leaders, parents, and workers [37]. Moreover, by 2050 more than one in three children will be living in SSA [38]; by 2080, SSA could have more youth than Asia [39]. The health and well-being of this sizeable population is, therefore, an important mandate [40]. With continued evidence of increasing EWE, particularly in SSA, there is a need to understand EWE impacts on SSA child and adolescent mental health, as well as preventive and coping measures.

Children are not little adults given their developing systems, physiological differences, behavioral differences (e.g., hand-to-mouth, spending more time on the ground, breathing in more air, engaging in risk-taking behaviours), and longer life expectancy. Thus, exposures to climate induced EWE affect the biological, psychosocial and cognitive development of children and adolescents, [41] who may have more intense mental health symptoms than adults [42]. There is an indication that adolescent girls living in low- and middle-income countries (LMICs) may be particularly vulnerable to the negative impacts of climate change and potentially from EWE [43]. One question is whether girls living in SSA should be specifically targeted in adaptation strategies given the gender dimension of climate change [44].

Although the mental health literature refers to environmental stressors and adverse childhood experiences [45], the focus on the impact of climate change, particularly for EWE is limited [46]. For example, the World Health Organization's Mental Health Gap Action Plan (2010) does not include climate change as a risk factor [47]. The 2018 Lancet Commission on Mental Health and the Sustainable Development Goals (SDGs) calls attention to the need to draw out more focus of climate change impacts on mental health, but specific focus on the impacts of EWE on child and adolescent health is missing [46]. Owen and colleagues highlight the health systems gaps in SSA, particularly for diagnosing and treating children and adolescents where there is a lack of African validated tools and call for more research particularly as the impact from EWEs is missing [48]. It is rather the literature from high-income countries (HICs) that predominately highlights the potential associated mental health risks after an EWE event such as post-traumatic stress disorder (PTSD), anxiety disorders, depression symptoms and behavioral disorders [3,49]. Although the associations are documented, prevalence estimates for these associations are limited. Kar and colleagues attempted to provide clinical verification of mental and behavioral disorders, using an international checklist, for Indian 
children and adolescents exposed to an EWE [50]. It is not clear whether other LMICs have adapted diagnostic tools from HICs or developed their own that could be used in Africa.

Studies from other regions have illustrated potential mental health impacts and risk factors from EWE [51,52]. In the United States, for example, children have been affected by mental health problems following natural disasters indicating direct effects (e.g., Hurricane Sandy; [53]). Observed effects include adverse impacts to children's cognitive development, capacity to regulate emotions, and academic performance [54,55]. A review describing increasing events of heavy precipitation and flooding in Germany argues that the indication is that children and adolescents are experiencing psychological effects, but that there is a need for more country-specific research [3]. A Polish study identified a higher trauma impact on student participants, aged 11-21, who were young and female after being exposed to a flood [56]. Risk factors include time spent in risk-prone areas, access to support networks, and timely treatment. The concern is that if left untreated, these mental health impacts could extend into adulthood. Another risk factor from exposure to an EWE on mental health is related to sleep and particularly the lack of sleep linked to EWE, with the current literature focusing on hurricanes, resulting in poor sleep quality and PTSD symptoms [16,57]. Furthermore, studies on the disruptive nature of EWE indicate an impact on mental health resulting from the effect on families, home life and the disruption of school attendance indicating indirect effects (e.g., in Mongolia) [21,58-60]. The data from LMICs appear to be limited. This systematic review will aid in identifying the gaps in the literature.

\subsection{Resilience and Adaptation to EWE}

Understanding the impacts and complexities surrounding immediate and long-term impacts of EWEs on children in general and SSA in particular is vital for adaption planning within multiple sectors (e.g., health, environment, planning, finance), and for already stressed and under-resourced health systems. Simultaneously, it is vital to understand what protects the mental health of SSA children and adolescents who are exposed to an EWE. Although there is a robust literature on the promotive and protective factors and processes that enable child and adolescent resilience, it is largely based on studies outside of SSA and studies that examine resilience to risks other than EWE [5]. Little is known about the adaptive capacity of children and adolescents in SSA who already face stressors from poverty, political and economic instability, burden of diseases, to name a few, and where the current adaptation capacity for climate change in general, and the health sector specifically, is inadequate $[26,61]$.

Our intention is that the findings of this review will provide researchers and policy makers with information about resilience-enabling mechanisms and mental health indicators-both for SSA and global publications such as the Lancet Countdown on climate change and health [20,62] — that advance adaptation strategies, as well as general health policies and strategies that will provide prevention of child and adolescent mental health difficulties associated with EWE in SSA. Although there is recognition that direct and indirect effects of climate change on mental health are complex and challenging $[11,20]$, the intention is that the literature will provide information for adaptation plans to be more nuanced to include child and adolescent mental health. Our goals also are to promote resilient health care infrastructures (including developing mental health diagnostic tools appropriate for SSA), to promote adequate risk communication to prevent mental health risks before and during EWE, to increase commitment to improving training of health care providers and educators in child mental health, as well as to inform the development of appropriate interventions, including school-based interventions $[17,48,58,63]$.

\section{Defining Child and Adolescent Resilience}

In this review, we will define child and adolescent resilience from a social-ecological or systemic perspective. From this perspective, resilience is a dynamic process that supports positive outcomes (such as normative development or mental health) despite exposure to risk (such as EWE). The process 
relies on the interaction of resources found within the child or adolescent (such as the stress response system) as well as within relational, sociocultural, and ecological systems $[64,65]$.

\section{Methods and Design}

This systematic review will be performed according to the 2009 Preferred Reporting Items for Systematic Reviews and Meta-Analyses (PRISMA) guidelines [66-68]. We will analyze research-based publications to highlight that sub-Saharan African children and adolescents need to be central to international agreements and dialogue to promote transgenerational justice and solidarity. To substantiate our argument, we will conduct a systematic review of the relevant quantitative and qualitative literature. We acknowledge that an update of the PRISMA guideline will be published in 2020. This approach will be used to map the existing literature on EWE impact on the mental health of children living in SSA.

\subsection{Research Objectives}

The aim of this review is to identify what the EWE-related risk and resilience factors are for the mental health of children and adolescents living in SSA.

The objectives of this systematic review are to:

1. Identify existing research linked to EWE impacts (direct and indirect) on child and adolescent mental health in SSA.

2. Identify potential risk and resilience factors in relation to EWE, as well as research gaps.

\subsection{Review Questions}

The main questions for this review are:

1. What impact/s (direct and indirect) are EWE having on sub-Saharan African child and adolescent mental health?

2. What resilience processes and adaptation measures are currently in place or proposed in SSA to protect children and adolescent mental health from EWE?

\subsection{Systematic Review}

A systematic review will be conducted. The studies will be selected using the following inclusion and exclusion criteria.

\subsubsection{Inclusion Criteria}

The criteria for included studies in this systematic review are:

- Articles in English only. Since French and Portuguese are key languages in SSA, we ran a test search in PubMed filtering to Sub-Saharan Africa and by date 1989-2020. We found a total of 164 papers of which four were in French and none in Portuguese. The four French papers were not relevant and thus we will only include English articles.

- Articles linked to an extreme weather event within the past 30 years.

- Peer-reviewed journal articles.

- Articles in relation to children's and/or adolescents' exposure to extreme weather events and impacts on their mental health.

- Children are defined as newborn to less than 10 years old.

- Adolescents are defined as 10-19 years old.

- Research on participants living in SSA.

- Studies on SSA migrants living in non-SSA countries who were exposed to an EWE in SSA.

- $\quad$ All study designs - qualitative, quantitative, and mixed.

- Type of publication—original studies, systematic and scoping reviews, letters and comments. 


\subsubsection{Exclusion Criteria}

Studies meeting the following criteria will be excluded from the systematic review:

- Articles about children in Algeria, Egypt, Libya, Morocco and Tunisia and outside of Africa.

- Articles covering normal psychology or cognition.

- Articles that include mental health tangentially (e.g., in the recommendations).

- Multiple articles based on the same data set. The article to be included will be the one that provides the clearest evidence of mental health impacts of EWE for children.

\subsubsection{Search Strategy}

The search strategy will be protocol driven, and will use "snowballing" and citation tracking to identify relevant articles.

In order to identify relevant research, the search strategy listed in Table 1 of the protocol will be used. Articles retrieved using the stated search strategy will be populated into EndNote. Studies will be retrieved using the following databases: MEDLINE via PubMed (bibliographic database of life sciences and biomedical information), Academic Search Premier, Africa-Wide, CINAHL (Cumulative Index of Nursing and Allied Health Literature), ERIC (Education Resources Information Center), Health Source Nursing Academic, PsycARTICLES (database of peer-reviewed articles published by the American Psychological Association and affiliated journals), PsycINFO (American Psychological Association database of peer-reviewed literature in behavioral science and mental health) (all via EBSCOHost platform), Scopus (which includes contents of Embase), Web of Science Core Collection, Biological Abstracts, SciELO Citation Index, KCI-Korean Journal Database, and Russian Science Citation Index (all via Web of Science platform). Databases will be searched for the period 1989 to the date of the actual search.

Table 1. PubMed Search strategy, modified as needed for other electronic databases.

\begin{tabular}{|c|c|c|}
\hline \multicolumn{3}{|c|}{ Population: } \\
\hline$\# 1$ & MeSH terms: & $\begin{array}{l}\text { Infant } \\
\text { Child } \\
\text { Adolescent } \\
\text { Young adult }\end{array}$ \\
\hline \#2 & Text Word: & $\begin{array}{l}\text { adolescent OR adolescents OR adolescence OR babies } \\
\text { OR baby OR boy OR boys OR child OR children OR girl } \\
\text { OR girls OR infant OR infants OR neonate OR neonates } \\
\text { OR newborn OR pediatric OR paediatric OR prenatal OR } \\
\text { teen OR teenager OR teenagers OR teens OR toddler OR } \\
\text { toddlers OR young adult or youth OR youths }\end{array}$ \\
\hline$\# 3$ & \#1 OR \#2 & \\
\hline \multicolumn{3}{|l|}{ Issue: } \\
\hline \#4 & MeSH terms: & $\begin{array}{l}\text { Weather } \\
\text { Climatic Processes } \\
\text { Disasters }\end{array}$ \\
\hline
\end{tabular}


Table 1. Cont.

avalanche OR avalanches OR climate change OR cyclone OR cyclones OR cyclonic OR drought OR droughts OR El Nina OR La Nina OR El Nino OR La Nino OR El Nino-southern oscillation OR extreme cold OR extreme heat OR extreme precipitation OR extreme temperature

\#5 Text Word: OR flood OR floods OR flooding OR global warming OR heat wave OR heatwave OR heavy precipitation OR heavy rain OR heavy rainfall OR global warming OR hurricane OR hurricanes OR landslide OR landslides OR mudslide OR mudslides OR natural disasters OR storm OR storms OR tidal wave OR tidal waves OR tornado OR tornadoes OR tsunami OR tsunamis OR wildfires OR weather OR weather-driven

\begin{tabular}{|c|c|c|}
\hline \#6 & \#4 OR \#5 & \\
\hline \multicolumn{3}{|c|}{ Evaluation: } \\
\hline$\# 7$ & MeSH terms: & $\begin{array}{l}\text { Mental Health } \\
\text { Mental Disorders } \\
\text { Adaptation, Psychological }\end{array}$ \\
\hline$\# 8$ & Text Word: & $\begin{array}{l}\text { alcohol use OR alcohol abuse OR anxiety OR attachment } \\
\text { disorders OR cognition OR cognitive OR coping OR } \\
\text { depression OR depressive OR drug use OR drug abuse } \\
\text { OR emotion OR emotions OR emotional OR mental OR } \\
\text { mood OR phobias OR post-traumatic OR posttraumatic } \\
\text { OR PTSD OR psychological OR psychology OR } \\
\text { psychosocial OR resilience OR resiliency OR sleep } \\
\text { disorders OR substance abuse OR substance use OR } \\
\text { temperament OR traumatic OR vulnerability OR } \\
\text { vulnerable populations }\end{array}$ \\
\hline$\# 9$ & \#7 OR \#8 & \\
\hline$\# 10$ & \#3 AND \#6 AND \#9 & \\
\hline$\# 11$ & Filter & $\begin{array}{l}\text { Sub-Saharan Africa filters } \\
\text { Date } 1989-2020\end{array}$ \\
\hline$\# 12$ & \#10 AND \#11 & \\
\hline
\end{tabular}

Reference lists of relevant papers retrieved by the search will be reviewed in order to identify additional papers as a means of "snowballing" [69]. Forward citation tracking of selected articles will be used to identify further relevant papers using citation tracking databases (e.g., Web of Science, Scopus, Ovid databases) [69].

\subsubsection{Methods for Study Selection}

Publications will be selected based on the review of titles and abstracts that were retrieved through the search strategy by two independent reviewers to ascertain eligibility. References will be excluded in line with the exclusion criteria. Publications fulfilling the inclusion criteria will be selected for a full text review. Any disagreements resulting in the selection of publications for full assessment will be re-evaluated, and if necessary, resolved through discussion with a third reviewer. The same reviewers will conduct full publication screening.

\subsection{Data Extraction}

This research will use a data extraction form to collect the data from each study. This form will be developed by the research team based on previously published and relevant data extraction forms $[70,71]$. Data extraction will be conducted independently by two authors. Both individuals 
will synthesize the selected publications by completing the spreadsheet developed by the research team. If there are disagreements during the data extraction process between these two members these will be discussed in order to reach consensus. Should this prove difficult, then a third team member will arbitrate.

Information and data will be extracted from the selected publications into an Excel spreadsheet created to record the characteristics and findings of the studies. Effects will be classified as direct or indirect from EWE based on the way the publication has reported the effects and whether or not there are intermediary events between exposure to EWE and mental health impacts, or other mediation effects. Based on the current literature, the authors will create categories of direct and indirect effects. The direct effects will include those following an exposure to high temperatures and heat, floods, storms, wildfires, droughts and landslides. Indirect effects, resulting in a disruption to children or adolescent's living situation, will be classified into categories identified by the authors such as, amplification of household social determinants of health (e.g., poverty, household economics), change in household structure (loss of parents, migration), and change in individual life structure (e.g., disruption of education). Where the publication does not state specifically, direct or indirect effects will be assessed by the research team based on existing literature. For example, studies that identify mental health impacts following displacement or migration may be classified as indirect if these effects are not identified as directly linked to the EWE.

Authors will not be contacted for incomplete data because this is beyond the scope of the review. The characteristics to be documented from all selected studies include: design of the study/data source, type of publication, study setting and geographic location (e.g., country, rural, urban), year of publication, year of event, target population characteristics (e.g., age range and sex if possible), extreme weather events referred to (both specific and general), mental health focus and impacts, sample size, research method, main findings (including outcome measures and those relating to risk and resilience), details to assess the risk of bias, recommendations and key limitations.

\subsection{Ethics}

Because the studies that will be retrieved will not contain identifiable data (i.e., not linkable to any individual), this systematic review does not require ethics approval. The proposal, however, has been submitted on PROSPERO (International Prospective Register of Ongoing Systematic Reviews [72]). The Reference Number is pending.

\subsection{Risk of Bias Assessment}

For each study selected, two members of the research team will independently review the papers for risk of bias. If there are differences in assessment between these two members these will be discussed in order to reach consensus. Should this prove difficult to achieve, then a third member of the team will play an arbitration role. The studies will be reviewed individually to assess whether the risk is low, high or unclear with both team members presenting the results in a table. The table will cover several elements, for example, selection bias (allocation concealment and random sequence generation), performance bias (blinding of participants or personnel where relevant), detection bias (blinding of outcome assessment), attribution bias (incomplete outcome data), reporting bias (selective reporting), transparency bias (industry funding, disclosed conflict of interest) and any others detected. The table categories will be designed by team members based on the literature reviewing tools for assessing risk of reporting biases [73]. These will be qualitatively assessed in relation to the expected impact on bias. The team will determine, after completing the table, what constitutes a "high risk of bias" and "high proportion" of studies which have a high risk of bias.

\subsection{Data Synthesis}

An independent consultant will be hired to run the searches based on the search strategy developed by the authors (research team) in May 2020. A narrative synthesis of the selected studies will be 
summarized in tables, as well as a narrative report written [74]. We are assuming meta-analysis will not be possible since we anticipate that limited studies will have been published on the mental health impacts from EWE on children and adolescents living in SSA. Furthermore, the studies that will be selected most likely will not have homogenous methods and therefore cannot be synthesized into a meta-analysis. For the quantitative studies selected, a meta-synthesis approach will be used [75]. The research team for this synthesis work (the authors of this paper) are from diverse backgrounds. The intention is to document the factors identified in the studies as potential mental health risks that should be addressed, or at least reviewed, for national adaptation strategies in SSA.

\section{Conclusions}

This systematic review will provide insights into risks (direct and indirect) and resilience for sub-Saharan African children and adolescents exposed to EWE with a focus on the impacts on child and adolescent mental health. The review will include both impacts that are both direct (following exposure to an EWE) and indirect (following a disruption to the living situation of children or adolescents such as forced migration, disruption of the family unit or caregiver capacity, or other disruption caused by the EWE). The intention is that this review will highlight key risk and resilience factors needing to be addressed by national adaption strategies, as well as climate change discussions globally, hopefully resulting in the development of specific EWE and mental health indicators for children and adolescents. The findings of this review will also be informative for general health policy and strategies to improve health systems management of mental health impacts from EWE on children and adolescents.

\section{Limitations}

One of the study's limitations is that only peer-reviewed articles in English will be included and this will then exclude research that may have been conducted in other languages particularly relevant to Francophone and Lusophone African countries.

Author Contributions: Conceptualization, H.-A.R.; Development of research strategy, H.-A.R., M.S., L.C.T., R.A.E., J.A.P., R.A.H.; Writing of proposal draft, H.-A.R.; Review and editing of proposal draft, H.-A.R., M.S., L.C.T., R.A.E., J.A.P., R.A.H. All authors have read and agreed to the published version of the manuscript.

Funding: This research received no external funding.

Acknowledgments: The research team thanks Katie Garrun and Jane Kelly for assisting with the database research strategy.

Conflicts of Interest: The authors declare no conflict of interest.

\section{References}

1. CDKN. The IPCC's Fifth Assessment Report: What's in It for Africa? CDKN: London, UK, 2014.

2. Pacheco, S.E. Catastrophic effects of climate change on children's health start before birth. J. Clin. Investig. 2020, 130, 562-564. [CrossRef] [PubMed]

3. Mambrey, V.; Wermuth, I.; Böse-O'Reilly, S. Extreme weather events and their impact on the mental health of children and adolescents. Bundesgesundh. Gesundh. Gesundh. 2019, 62, 599-604. [CrossRef] [PubMed]

4. Rataj, E.; Kunzweiler, K.; Garthus-Niegel, S. Extreme weather events in developing countries and related injuries and mental health disorders-A systematic review. BMC Public Health 2016, 16, 1-12. [CrossRef]

5. Masten, A.S. Ordinary Magic: Resilience in Development; Guilford Publications: New York, NY, USA, 2014; p. 370.

6. Majeed, H.; Lee, J. Comment The impact of climate change on youth depression and mental health. Lancet Planet Health 2017, 1, 94-95. [CrossRef]

7. Martinez Garcia, D.; Sheehan, M.C. Extreme weather-driven disasters and children's health. Int. J. Health Serv. 2016, 46, 79-105. [CrossRef]

8. Drumond, A.; Liberato, M.L.R.; Reboita, M.S.; Taschetto, A.S. Weather and Climate Extremes: Current Developments. Atmosphere 2020, 11, 24. [CrossRef] 
9. Pollack, A.A.; Weiss, B.; Trung, L.T. Mental health, life functioning and risk factors among people exposed to frequent natural disasters and chronic poverty in Vietnam. BJPsych Open 2016, 2, 221-232. [CrossRef]

10. Vins, H.; Bell, J.; Saha, S.; Hess, J.J. The mental health outcomes of drought: A systematic review and causal process diagram. Int. J. Environ. Res. Public Health 2015, 12, 13251-13275. [CrossRef]

11. Hayes, K.; Blashki, G.; Wiseman, J.; Burke, S.; Reifels, L. Climate change and mental health: Risks, impacts and priority actions. Int. J. Ment. Health Syst. 2018, 12, 1-12. [CrossRef]

12. Curtis, S.; Fair, A.; Wistow, J.; Val, D.V.; Oven, K. Impact of extreme weather events and climate change for health and social care systems. Environ. Health A Glob. Access Sci. Sour. 2017, 16 (Suppl. 1), 128-132. [CrossRef]

13. Keenan, H.T.; Marshall, S.W.; Nocera, M.A.; Runyan, D.K. Increased incidence of inflicted traumatic brain injury in children after a natural disaster. Am. J. Prev. Med. 2004, 26, 189-193. [CrossRef] [PubMed]

14. Watts, N.; Amann, M.; Arnell, N.; Ayeb-Karlsson, S.; Belesova, K.; Boykoff, M.; Byass, P.; Cai, W.; Campbell-Lendrum, D.; Capstick, S.; et al. The 2019 report of The Lancet Countdown on health and climate change: Ensuring that the health of a child born today is not defined by a changing climate. Lancet 2019, 394, 1836-1878. [CrossRef]

15. Berry, H.L.; Bowen, K.; Kjellstrom, T. Climate change and mental health: A causal pathways framework. Int. J. Public Health 2010, 55, 123-132. [CrossRef]

16. Burke, S.E.L.; Sanson, A.V.; Hoorn, J.V. The Psychological Effects of Climate Change on Children. Curr. Pshychiatry Rep. 2018, 20. [CrossRef]

17. Cousins, S. Extreme weather events and child health. Lancet Child Adolesc. Health 2019, 3, 70-71. [CrossRef]

18. Easterling, D.R.; Kunkel, K.E.; Wehner, M.F.; Sun, L. Detection and attribution of climate extremes in the observed record. Weather Clim. Extrem. 2016, 11, 17-27. [CrossRef]

19. Ramin, B.M.; McMichael, A.J. Climate change and health in sub-saharan Africa: A case-based perspective. Ecohealth 2009, 6, 52-57. [CrossRef]

20. Watts, N.; Amann, M.; Arnell, N.; Ayeb-Karlsson, S.; Belesova, K.; Berry, H.; Bouley, T.; Boykoff, M.; Byass, P.; Cai, W.; et al. The 2018 report of the Lancet Countdown on health and climate change: Shaping the health of nations for centuries to come. Lancet 2018, 392, 2479-2514. [CrossRef]

21. Groppo, V.; Kraehnert, K. Extreme Weather Events and Child Height: Evidence from Mongolia. World Dev. 2016, 86, 59-78. [CrossRef]

22. Serdeczny, O.; Adams, S.; Baarsch, F.; Coumou, D.; Robinson, A.; Hare, W.; Schaeffer, M.; Perrette, M.; Reinhardt, J. Climate change impacts in Sub-Saharan Africa: From physical changes to their social repercussions. Reg. Chang. 2017, 17, 1585-1600. [CrossRef]

23. Engelbrecht, F.; Adegoke, J.; Bopape, M.-J.; Naidoo, M.; Garland, R.; Thatcher, M.; McGregor, J.; Katzfey, J.; Werner, M.; Ichoku, C.; et al. Projections of rapidly rising surface temperatures over Africa under low mitigation. Environ. Res. Lett. 2015, 10, 85004. [CrossRef]

24. Fitchett, J.M.; Grab, S.W. A 66-year tropical cyclone record for south-east Africa: Temporal trends in a global context. Int. J. Climatol. 2014, 34, 3604-3615. [CrossRef]

25. Chersich, M.F.; Wright, C.Y. Climate change adaptation in South Africa: A case study on the role of the health sector. Glob. Health 2019, 15. [CrossRef] [PubMed]

26. Chersich, M.F.; Wright, C.Y.; Venter, F.; Rees, H.; Scorgie, F.; Erasmus, B. Impacts of climate change on health and wellbeing in South Africa. Int. J. Environ. Res. Public Health 2018, 15, 1884. [CrossRef]

27. Sawyer, S.M.; Azzopardi, P.S. Viewpoint The age of adolescence. Lancet Child Adolesc. Health 2018, 2, $223-228$. Available online: www.thelancet.com/child (accessed on 20 August 2019). [CrossRef]

28. African Union. African Youth Charter. The Gambia. 2006. Available online: https://au.int/en/treaties/africanyouth-charter (accessed on 20 August 2019).

29. Honwana, A. Youth, waithood, and protest movements in Africa. In Proceedings of the African Dynamics in a Multipolar World: 5th European Conference on African Studies, Lisbon, Portugal, 27-29 June 2014; pp. 2428-2447.

30. Dyregrov, A.; Yule, W.; Olff, M. Children and Natural Disasters. Eur. J. Psychotraumatol. 2018, 9. [CrossRef]

31. Gibbons, E.D. Climate change, children's rights, and the pursuit of intergenerational climate justice. Health Hum. Rights 2014, 16, 19-31.

32. Bhutta, Z.A.; Aimone, A.; Akhtar, S. Climate change and global child health: What can paediatricians do? Arch. Dis. Child. 2019, 104, 417-418. [CrossRef] 
33. Salas, R.N.; Jacobs, W.; Frederica, P. The Case of Juliana v. U.S.-Children and the Health Burdens of Climate Change. N. Engl. J. Med. 2019, 380, 2085-2087. [CrossRef]

34. Philipsborn, R.P.; Chan, K. Climate Change and Global Child Health. Pediatrics 2018, 141, e20173774. [CrossRef]

35. Swaminathan, A.; Lucas, R.; Harley, D.; McMichael, A. Will Global Climate Change Alter Fundamental Human Immune Reactivity: Implications for Child Health? Children 2014, 1, 403-423. [CrossRef] [PubMed]

36. UNICEF. Adolescent Demographics. 2016. Available online: https://data.unicef.org/topic/adolescents/ demographics/ (accessed on 20 August 2019).

37. Marquer, C.; Barry, C.; Mouchenik, Y.; Djibo, D.M.; Manzo, M.L.; Maza, E.M.T.; Githaiga, S.; Casas, G.; Kirubi, B.W.; Marichez, H.; et al. Screening for psychological difficulties in young children in crisis: Complementary cross-cultural validation. Int. Health 2015, 7, 438-446. [CrossRef] [PubMed]

38. UNICEF. Children in Africa. Key Statistics on Child Survival, Protection and Development; UNICEF: New York, NY, USA, 2015.

39. United Nation Department of Economic and Social Affairs Population Devision. Youth Population Trends and Sustainable Development; United Nation Department of Economic and Social Affairs Population Devision: New York, NY, USA, 2015; pp. 1-4. Available online: www.unpopulation.org (accessed on 8 April 2020).

40. O'Malley, J.; Wardlaw, T.; You, D.; Hug, L.; Anthony, D. Africa's child demographics and the world's future. Lancet 2014, 384, 730-732. [CrossRef]

41. Sheffield, P.E.; Landrigan, P.J. Global climate change and children's health: Threats and strategies for prevention. Environ. Health Perspect. 2011, 119, 291-298. [CrossRef]

42. Xu, Z.; Sheffield, P.E.; Hu, W.; Su, H.; Yu, W.; Qi, X.; Tong, S. Climate change and children's health-A call for research on what works to protect children. Int. J. Environ. Res. Public Health 2012, 9, 3298-3316. [CrossRef]

43. Atkinson, H.G.; Bruce, J. Adolescent girls, human rights and the expanding climate emergency. Ann. Glob. Health 2015, 81, 323-330. [CrossRef]

44. Swarup, A.; Dankelman, I.; Ahluwalia, K.; Hawrylyshgn, K. Weathering the Storm: Adolescent Girls and Climate Change; Plan International: London, UK, 2011.

45. Brown, D.W.; Anda, R.F.; Tiemeier, H.; Felitti, V.J.; Edwards, V.J.; Croft, J.B.; Giles, W.H. Adverse childhood experiences and the risk of premature mortality. Am. J. Prev. Med. 2009, 37, 389-396. [CrossRef]

46. Patel, V.; Saxena, S.; Lund, C.; Thornicroft, G.; Baingana, F.; Bolton, P.; Chisholm, D.; Collins, P.Y.; Cooper, J.L.; Eaton, J.; et al. The Lancet Commission on global mental health and sustainable development. Lancet 2018, 392, 1553-1598. [CrossRef]

47. WHO. MHGap Intervention Guide for Mental, Neurological and Substance Use Disorders in Non-Specialised Mental Health Settings; WHO: Geneva, Switzerland, 2010.

48. Owen, J.P.; Baig, B.; Abbo, C.; Baheretibeb, Y. Child and adolescent mental health in sub-Saharan Africa: A perspective from clinicians and researchers. BJPsych Int. 2016, 13, 45-47. [CrossRef]

49. Lai, B.S.; Osborne, M.C.; Piscitello, J.; Self-Brown, S.; Kelley, M.L. The relationship between social support and posttraumatic stress symptoms among youth exposed to a natural disaster. Eur. J. Psychotraumatol. 2018, 9 (Suppl. 2), 1450042. [CrossRef]

50. Kar, N.; Mohapatra, P.K.; Nayak, K.C.; Pattanaik, P.; Swain, S.P.; Kar, H.C. Post-traumatic stress disorder in children and adolescents one year after a super-cyclone in Orissa, India: Exploring cross-cultural validity and vulnerability factors. BMC Psychiatry 2007, 7, 1-9. [CrossRef]

51. Brown, R.C.; Witt, A.; Fegert, J.M.; Keller, F.; Rassenhofer, M.; Plener, P.L. Psychosocial interventions for children and adolescents after man-made and natural disasters: A meta-analysis and systematic review. Psychol. Med. 2017, 47, 1893-1905. [CrossRef]

52. Sattler, D.N.; Preston, A.J.; Kaiser, C.F.; Olivera, V.E.; Valdez, J.; Schlueter, S. Hurricane Georges-A cross-national study examining preparedness, resource loss, and psychological distress in the U.S. Virgin Islands, Puerto Rico, Dominican Republic, and the United States. J. Trauma. Stress 2002, 15, 339-350. [CrossRef]

53. Neria, Y.; Shultz, J. Mental Health Effects of Hurricane Sandy. JAMA J. Am. Med. Assoc. 2012, 308, $2571-2572$. [CrossRef]

54. US Global Change Research Program. The Impacts of Climate Change on Health in the United States: A Scientific Assessment; US Global Change Research Program: Washington, DC, USA, 2016. 
55. Sheffield, P.E.; Uijttewaal, S.A.M.; Stewart, J.; Galvez, M.P. Climate change and schools: Environmental hazards and resiliency. Int. J. Environ. Res. Public Health 2017, 14, 1397. [CrossRef]

56. Bokszczanin, A. Prevalence and Psychological Correlates of Complicated. J. Trauma. Stress 2007, 20, 347-351. [CrossRef]

57. Rifkin, D.I.; Long, M.W.; Perry, M.J. Climate change and sleep: A systematic review of the literature and conceptual framework. Sleep Med. Rev. 2018, 42,3-9. [CrossRef]

58. Codreanu, T.A.; Celenza, A.; Jacobs, I. Does disaster education of teenagers translate into better survival knowledge, knowledge of skills, and adaptive behavioral change? A systematic literature review. Prehosp. Disaster Med. 2014, 29, 629-642. [CrossRef]

59. Kiang, K.; Graham, S.; Farrant, B. Climate change, child health and the role of the paediatric profession in under-resourced settings. Trop. Med. Int. Health 2013, 18, 1053-1056. [CrossRef]

60. McMichael, C.; Barnett, J.; Mcmichael, A.J. Review An Ill Wind? Climate Change, Migration, and Health. Environ. Health Perspect. 2012, 120, 646-654. Available online: http://www.ncbi.nlm.nih.gov/pmc/articles/ PMC3346786/pdf/ehp.1104375.pdf (accessed on 6 January 2020). [CrossRef]

61. Ibe, G.O.; Amikuzuno, J. Climate change in Sub-Saharan Africa: A menace to agricultural productivity and ecological protection. J. Appl. Sci. Environ. Manag. 2019, 23, 329. [CrossRef]

62. Hayes, K.; Poland, B. Addressing mental health in a changing climate: Incorporating mental health indicators into climate change and health vulnerability and adaptation assessments. Int. J. Environ. Res. Public Health 2018, 15, 1806. [CrossRef]

63. Kreslake, J.M.; Price, K.M.; Sarfaty, M. Developing effective communication materials on the health effects of climate change for vulnerable groups: A mixed methods study. BMC Public Health 2016, 16, 1-15. [CrossRef]

64. Masten, A.S.; Cicchetti, D. Resilience in development: Progress and transformation. In Developmental Psychopathology: Risk, Resilience, and Intervention; Cicchetti, D., Ed.; John Wiley \& Sons Inc.: New York, NY, USA, 2016; pp. 271-333.

65. Ungar, M.; Theron, L. Resilience and mental health: How multisystemic processes contribute to positive outcomes. Lancet Psychiatry 2019. online pre. [CrossRef]

66. Tricco, A.C.; Lillie, E.; Zarin, W.; O’Brien, K.K.; Colquhoun, H.; Levac, D.; Moher, D.; Peters, M.; Horsley, T.; Weeks, L.; et al. PRISMA extension for scoping reviews (PRISMA-ScR): Checklist and explanation. Ann. Intern. Med. 2018, 169, 467-473. [CrossRef]

67. Peters, M.D.J.; Godfrey, C.M.; Khalil, H.; McInerney, P.; Parker, D.; Soares, C.B. Guidance for conducting systematic scoping reviews. Int. J. Evid. Based Healthc. 2015, 13, 141-146. [CrossRef]

68. Moher, D.; Shamseer, L.; Clarke, M.; Ghersi, D.; Liberati, A.; Petticrew, M.; Shekelle, P.; Stewart, L.A. Preferred reporting items for systematic review and and explanation meta-analysis protocols (PRISMA-P) 2015: Elaboration. BJM 2015, 349, 1-25. [CrossRef]

69. Greenhalgh, T.; Peacock, R. Effectiveness and efficiency of search methods in systematic reviews of complex evidence: Audit of primary sources. Br. Med. J. 2005, 331, 1064-1065. [CrossRef]

70. Jefferis, T.C.; Theron, L.C. Explanations of resilience in women and girls: How applicable to black South African girls. Womens Stud. Int. Forum 2018, 69, 195-211. [CrossRef]

71. van Breda, A.D.; Theron, L.C. A critical review of South African child and youth resilience studies, $2009-2017$. Child Youth Serv. Rev. 2018, 91, 237-247. [CrossRef]

72. National Institute for Health Research. PROSPERO. 2019. Available online: https://www.crd.york.ac.uk/ prospero/ (accessed on 8 April 2020).

73. Page, M.J.; McKenzie, J.E.; Higgins, J.P.T. Tools for assessing risk of reporting biases in studies and syntheses of studies: A systematic review. BMJ Open 2018, 8, 1-16. [CrossRef] [PubMed]

74. Kastner, M.; Tricco, A.C.; Soobiah, C.; Lillie, E.; Perrier, L.; Horsley, T.; Welch, V.; Cogo, E.; Antony, J.; Straus, S.E. What is the most appropriate knowledge synthesis method to conduct a review? Protocol for a scoping review. BMC Med. Res. Methodol. 2012, 12, 1-10. [CrossRef] [PubMed]

75. Lachal, J.; Revah-Levy, A.; Orri, M.; Moro, M.R. Metasynthesis: An original method to synthesize qualitative literature in psychiatry. Front. Psychiatry 2017, 8. [CrossRef] [PubMed]

(C) 2020 by the authors. Licensee MDPI, Basel, Switzerland. This article is an open access article distributed under the terms and conditions of the Creative Commons Attribution (CC BY) license (http://creativecommons.org/licenses/by/4.0/). 